\title{
Writing Cannot Tell Everything
}

\author{
Jan Baetens
}

\begin{abstract}
:
This chapter addresses the topic of the mixte (English: the mixt), a type of writing that combines very different, sometimes perhaps even incompatible types of writing, such as fiction and non-fiction or, in a more singular manner, fiction and writing on fiction (the term of mixt has been coined by author and theoretician Jean Ricardou). However, the present chapter does not just present or examine Ricardou's theory and practice of the mixt but takes it as its starting point to reflect on the status of the author's self-commentary in a research-oriented fictional practice. More precisely, the chapter makes a plea, not for the merger but the articulation (and thus the relative separation) of fiction and writing on fiction in practice-based artistic research.
\end{abstract}

\section{Limits and Pitfalls of Creative Writing as Practice-Based Research}

As clearly argued by Corina Caduff, the theory and practice of artistic research remain underdeveloped in the field of literature. The opening claim of her 2009 contribution to the debate still holds today:

In its beginnings in the 1990s the artistic research discourse centered mainly on the visual arts from which it arose. In recent years, however, an increasing number of relevant studies have appeared from the fields of design, theater, and film - joined increasingly by music and dance-in the context of artistic research. . . . In what follows, a field will be discussed that, to the best of my knowledge, has yet to be raised in the debates about artistic research: literature. ${ }^{1}$

The following pages should be read as a brief comment on this observation from the geographic and cultural perspective of France, where contrary to most of the Anglo-Saxon and Scandinavian countries discussed by Caduff there is hardly any tradition of $\mathrm{PhD}$ programmes in creative writing. Things are changing, true, but slowly, and the aim of my remark is of course not to suggest

1 Corina Caduff, "Literature and Artistic Research," in: Corina Caduff et al., eds., Art and Artistic Research. Zurich: Scheidegger \& Spiess, 2009, pp. 98-105: here p. 98. 
that there is no tradition of artistic practice in literature in France. What I would like to make clear in this contribution is the importance and originality of a particular French theoretical and practical intervention in the debates on literary creativity, which concerns the need to shift from the traditional idea of the author as a genius to the modern, explicitly democratic idea of the author as crafts(wo)man and producer. This is related to less academic forms of theorising practice, another key dimension of French literary life, where ideas on literature and how to write have always been less determined by academic gatekeepers than by the authors themselves, who like to elaborate their personal claims and convictions in treatises. ${ }^{2}$

In more general terms, the tradition of practice-based research can be said to be both well established and poorly recognised in the literary field. On the one hand, literary writing has, for a long time, often been practised as an experiment relying on a wide set of models, hypotheses, and techniques. This is what many authors do intuitively, as demonstrated for instance by Gustave Flaubert, whose letters contain countless reflections on the art of writing, ${ }^{3}$ or Henry James's prefaces to the edition of his complete novels eventually republished under the title The Art of the Novel. ${ }^{4}$ In quite some cases, authors even work with an explicit programme, which they either illustrate or put to the test when starting to write. Edgar Allan Poe's Philosophy of Composition, ${ }^{5}$ Raymond Roussel's How I Wrote Certain of My Books, ${ }^{6}$ Oulipo's use of literary 'constraints' or preformatted rules that steer and foster the literary imagination, ${ }^{7}$ these are all examples of the many ways in which authors foreground the mutual involvement of theory and practice. On the other hand, there is also a strong resistance to link theory and practice. The current difficulties with understanding or reshaping creative writing as a form of artistic research - that is of the rational and methodologically enhanced production of new insights and new knowledge - is a symptom of this resistance. This is why creative writing, as it

2 A famous case for this was Sartre's What is Literature? Jean-Paul Sartre, What is Literature? (1948), translated by Bernard Frechtman. London: Methuen, $195^{\circ}$.

3 Gustave Flaubert, The Letters of Gustave Flaubert, 1857-1880 (1887-1893), translated and ed. by Francis Steegmuller. Cambridge, MA: Belknap Press, 1984.

4 Henry James, The Art of the Novel: Critical Prefaces (1909). Chicago, IL: The University of Chicago Press, 2011.

5 Edgar Allan Poe, "The Philosophy of Composition" (1846), in: The Complete Poetry of Edgar Allan Poe. New York, NY: Signet Classics, 1996, pp. 503-512.

6 Raymond Roussel, How I Wrote Certain of My Books (1935), translated by Trevor Winkfield. Cambridge, MA: Exact Change, 2005.

7 Warren F. Motte, Oulipo: A Primer of Potential Literature. McLean, IL: Dalkey Archive, 1986. 
is generally practised and theorised today either inside or outside academia, ${ }^{8}$ isn't necessarily the best answer to the ongoing developments of practicebased research and $\mathrm{PhD}$ programmes, as will become clear in the remainder of this chapter.

Is creative writing in itself a form of practice-based research? In theory, the answer should be yes, provided this type of writing does what research is supposed to do, namely establishing a productive interaction with a given theory, selecting an adequate method, defining one or more research questions and, last but not least, producing a set of falsifiable answers to these questions while equally giving a meaningful feedback on method as well as theory. Nevertheless, in practice, most existing creative writing programmes do not comply with such an approach to research. To pursue it, they have to be changed radically. On the one hand, it will prove necessary to dismantle the separation of creative writing and (literary, critical, and cultural) theory, which belong to completely different curricula with different staff and different students addressing completely different questions. In other words, what has to change is the very input of the creative writing programmes: the individual project of the student is no longer sufficient; he or she will also have to address more general and therefore more theoretical issues. On the other hand, it will be no less imperative to also enlarge the programmes' output: instead of only delivering a work of fiction (or creative non-fiction), the student of the creative writing programme will have to complement this production with a second text, a theoretical and methodological supplement in which he or she reflects upon both the process and the result of the creative work. This is what generally happens when creative writing programmes plan to enlarge their course offerings in order to include practice-based PhDs. To quote just one but very representative example:

The PhD in Creative Writing provides the capstone to the postgraduate Creative Writing programme at Edinburgh, offering students graduating from the MSc in Creative Writing an opportunity to undertake work at a higher level, aimed towards the production of a substantial, publishable piece of creative writing, accompanied by a sustained exercise in critical study. 9

8 Anglo-Saxon creative writing programmes are mostly located within academia, while the continental tradition of ateliers d'écriture or literary workshops doesn't necessarily rely on academia. Cf. Mark McGurl, The Program Era. Cambridge, MA: Harvard University Press, 2009.

9 http://www.ed.ac.uk/literatures-languages-cultures/english-literature/postgraduate/phd/ creative-writing, date of access: 17 Sept. 2018. 
The changes in input, which are mainly institutional, are easier to handle than those in output, which concern the very heart of practice-based research in literary writing. Even if the gap between theory and creative writing is very deep, the design of a new, mixed curriculum is certainly not impossible. The simultaneous articulation of creative writing and critical study, however, raises very different questions, given the radical difference in nature between both types of writing. The combination of creative writing and critical study is a challenging, risky task, and can even prove harmful in more than one regard.

Firstly, one might ask whether it is possible to catch the specificity of literary writing in a supplementary text that is not itself literary, but didactic, informing, instructive, etc. Even if one rejects the outdated romantic idea that a literary text can only be experienced and not explained, the fundamental question remains whether it is possible to provide such an explanation in a non-literary text. Should the critical supplement rather be a piece of writing itself? Examples for this kind of problem might be, for instance, the poetics of allusions or irony, for as soon as one makes explicit the mechanism of allusion or the functioning of irony, one also destroys their effect. And yet this issue might not be equally grave in all kinds of texts. For instance, in texts that Roland Barthes, in 1970, called lisible texts-which do not specifically challenge the reader's habits and expectations - the unpacking of allusions or of irony is less problematic than in what Barthes called scriptible texts: in the former, the disclosing of the hidden reference is welcomed as a useful help to the reader, in the latter, the same intervention may destroy the reader's creative struggle with the writing. ${ }^{10}$

Secondly, and provided one succeeds in turning the critical supplement into a real literary text, one may ask whether such a transformation does not jeopardise the 'scientific' character of the commentary, which must be transparent to all and open to intersubjective debate and remediation. Will the literary version of critical commentary be able to provide new objective knowledge, or will its gain in knowledge depend on mere intuition and subjective interpretation, both on the part of the author-researcher and the reader? To discuss this problem it might be helpful to remember Ricardou's distinction between lecturable and lisible texts, presented some ten years after Barthes's discussion

10 Barthes's terms are usually translated as readerly and writerly texts, although a more literal translation would be 'readable' and 'writable.' While the former term refers to rather conventional texts that do not confront the read with any challenges, the latter means a kind of textual practice that challenges the readers, while also giving them a special kind of pleasure and bliss. Cf. Roland Barthes, S/Z. An Essay (1970), translated by Richard Miller. New York, NY: Farrar, Straus and Giroux, 1974 and The Pleasure of the Text (1972), translated by Richard Miller. New York, NY: Farrar, Straus and Giroux, 1975 . 
of the lisible/scriptible distinction. For Ricardou, lecturable refers to what can be clearly understood in a text (lecturable is a neologism one could translate as 'technically understandable'), while the latter term, lisible, refers to what pleases the reader (lisible is a very general term which takes here the special meaning of 'pleasant to read').11

According to Ricardou, any text can always be framed through the double lens of the lecturable and the lisible - since all texts teach us something we like or dislike in some way - and this necessary intertwinement can explain why any straightforward transformation of the critical analysis into a second piece of creative writing is dangerous: while creative writing cannot but emphasise the importance of the lisible, critical analysis has to foreground the role of the lecturable. Another difficulty is that the implicit sequential arrangement of both parts-first comes the writing, then comes the analysis-does not always reflect the actual process, which can include many feedback loops. The analysis can precede the writing or interrupt and change it, for example, which complicates the very distinction between both text types.

\section{The Articulation of Writing and Criticism: Towards a Writing of the mixt}

Given the various difficulties one encounters when one supplements the literary text with a didactic, informative supplement and when one tries to present this critical supplement in a literary form, it is understandable that advocates of practice-based research have tried to radically merge both aspects in one single text. Either they make the analysis part of the writing or they set out

11 Cf. Jean Ricardou, "Eleménts de textique (I)," in: conséquences 10 (1987), pp. 5-28: here p. 17. At first sight, one may have the impression that the tandem lecturable/lisible is a reformulation of Barthes's lisible/scriptible distinction, but the differences are more significant than the similarities. In Barthes, the competing terms designate two different text types (a text, or a fragment of a text, is either lisible or scriptible), whereas the Ricardolian terms describe a more dialectic relationship, according to which each text can be read as both lecturable and lisible. Moreover, the relationship between both reader reactions is anything except direct and linear. One might think, for instance, that very lecturable texts are also very lisible (for we tend to like more what we understand) or, the other way round, that very lisible texts are also lecturable (for we read better when we like what we read). In practice, this is not always the case: On the one hand, certain readers are emotionally triggered by cognitive thresholds, so that a problem in lecturabilité can prove a springboard for lisibilité. On the other hand, texts that are lisible do not always engender good critical readings (this is perhaps what we say by stating that reading for fun and reading for criticism are seen as mutually incompatible). 
from the analysis but tend to transform it into the writing practice itself. The second traditionally happens in the various forms of the ars poetica genre, where text and programme, creative output and theoretical input, aim at coinciding as seamlessly as possible. But there are many other ways in which a creative text can be given a self-revelatory twist. A good point in case is the countless occurrences of the mise en abyme-a technique that establishes a mirror effect between part and whole of the text - thus making a certain detail reveal one or more aspects of the complete text like the play within the play in Hamlet. ${ }^{12}$ In modernist texts, this internal didacticism can tend to complete self-referentiality. In that case, the work is composed in such a way that all its elements mirror its own structure. This happens in certain types of conceptual poetry (we all know examples of poems stating that 'this text is made of seven words', for instance) as well as in avant-garde novels. (The French New Novel, in particular, has often been analysed in this perspective.)

One of the most detailed and sophisticated examples of such a take on writing has been proposed by Ricardou, who published a piece of writing, La Prise de Constantinople (1965), which aspired at complete self-referentiality. ${ }^{13}$ More than a dozen years later, he complemented his novel with a very long critical analysis in which he made explicit the implicitly designated rules of the production, structure, and functioning of the work. ${ }^{14}$ This a posteriori critical analysis obviously betrays the failure of the initial programme. If it is necessary to add such a long commentary, this implies that the original text did not reach its own objective to self-reflexively render its composition transparent. In other words: If it was actually possible to read in Ricardou's novel what it claims to display and demonstrate, namely the mechanisms of its own genesis and composition, then the subsequent production of a critical analysis could only be seen as an attempt to remediate the novel's flaws.

Similar problems occur when the blurring of the boundaries between creative writing and critical analysis is not pursued at the level of the piece of writing, as in the case of La Prise de Constantinople, but sets out from the theoretical analysis itself. The desire to conceive one's own critical and theoretical discourse as a form of (creative) writing is certainly not new, as demonstrated by the stylistic ambitions_-and qualities! — of many critics. Yet it has become one of the fundamental characteristics of French poststructuralist critical

12 Lucien Dällenbach, The Mirror in the Text (1975), translated by Jeremy Whitely. Chicago, IL: The University of Chicago Press, 1977.

13 Jean Ricardou, La Prise de Constantinople (1965), in: Lintégrale Jean Ricardou. Tome 2: La Prise de Constantinople et autres écrits. 1962-1966. Brussels: Les Impressions Nouvelles 2018, pp. 139-351.

14 Jean Ricardou, "La Fiction à mesure," in: Nouveaux Problèmes du roman. Paris: Les Éditions du Seuil, 1978, pp. 244-351. 
writing, such as most famously represented by Roland Barthes, Jacques Derrida, among others. ${ }^{15}$ In such texts, one can often observe that a multiplication of glosses, paraphrases, commentaries, exegeses, and other continuations hint at the difficulty of striking the right balance between writing and analysis. This can appear as if the tendency to always add supplementary details and further sophistications were the symptoms of the tragic awareness that no text or formula will ever be capable of really fixing or pinpointing the unlimited possibilities of a text.

In all cases discussed so far, be it the radical separation of writing and analysis (as in most current example of creative writing $\mathrm{PhD}$ programmes) or the no less radical attempts at merging both text types into one (as in the experimental praxis of certain avant-garde writers and critics, sometimes imitated in creative writing programmes), we have encountered a fundamental and recurring problem: one always explains either too much or not enough. However, it is feasible to think of a third strategy of linking creative writing and critical analysis, which avoids some of the issues of either separation or blending. This strategy maintains the tension and difference between the two types of writing, but it does so within one text itself. In other words: It neither creates a diptych out of a piece of creative writing and a sample of critical analysis nor tries to invent new ways of writing that merge the two text types and erase or cover up their essential differences. Such a procedure can be based on the montage of different text types-in this case creative writing and critical analysis. But other kinds of montage are relevant as well, between poetry and prose, fiction and non-fiction, high and low, narrative and argumentative, specialised and vulgarising, schematic and detailed, etc.

Montage is, of course, a multifaceted notion, and it should be clear that the type of montage in question is not that of the Hollywood continuity editing, which tries to leave montage 'invisible' in order to naturalise and thus make imperceptible the technical devices of storytelling. Instead, a point of reference might be Sergei Eisenstein's intellectual montage, where the meaning-making effects are derived from the visible clash between heterogeneous elements. In literature, a good example of such montage is the concept of the mixt, which Ricardou presented four years after his aforementioned critical piece about the self-reflexive novel. This new text is called Le Théâtre des metamorphoses (1982), and-logically! —it both critically comments and practically applies the new notion of the mixt in a wide range of forms. ${ }^{16}$ The new notion, as well

\footnotetext{
15 Serge Doubrovsky, The New Criticism in France (1966), translated by Derek Coltman. Chicago, IL: The University of Chicago Press, 1973.

16 Jean Ricardou, Le Théâtre des métamorphoses. Paris: Les Éditions du Seuil, 1982.
} 
as the procedure, can be seen as direct consequences of Ricardou's failed attempts to, first, elaborate a totally self-referential fiction and, second, complement this fiction with the help of an autonomous critical essay.

A key feature of the mixt is to be found in Ricardou's accompanying definition of the 'text,' once again a general term redefined in a completely idiosyncratic manner. For Ricardou's, the word 'text' does not simply refer to any kind of written utterance but designates a very singular subsection of these utterances. If all writings have, at least in principle, a referential function (they refer to something that is outside the words), some writings have also a function that is self-referential (they refer to one or more aspects of their own structure). Verbal compositions whose function is referential or representative are occurrences of what Ricardou calls 'writing', while verbal compositions whose function is self-referential or meta-representative are occurrences of 'text.' The mixt is then not only the montage of different forms and styles of discourse, it is more fundamentally the strategy that relies on the combination of these forms to explore the tension between 'writing' and 'text,' or if one prefers between representation and meta-representation. ${ }^{17}$

\section{The Mixt as a Model for Practice-Based Research}

The tension between 'writing' and 'text,' I would like to argue, is the most basic problem that should be addressed in debates on creative writing as a form of practice-based research. If creative writing and critical analysis stay apart, something will be lost on both sides. The 'writing' of the critical analysis will never be able to tackle all the 'textual' dimensions of the creative piece, while at the same time the split between both may suggest that the critical essay accompanying the creative part of the diptych does not have to take into account its own 'textual' structures and dimensions. If both parts are merged, the problems may be even worse, since it may lead to a neglect of the challenging yet problematic relationship of lisible and lecturable. A solution to these problems is provided by the mixt, which is not only a kind of collage but also a form of negative dialectics. In the mixt, the two forces, which cannot be superseded in a synthetic reconciliation, appear in opposition to and next to each other. In such a way, the mixt does not abolish the differences between creative writing and critical analysis, but neither does it exclude the possibility of their mutual enrichment. In Ricardou's terms, 'writing' does not have to be confused with

17 Jean Ricardou, "How to Reduce Fallacious Representative Innocence. Word by Word Interview with Michel Sirvent," in: Studies in 2oth-Century Literature 15:2 (1991), pp. 277-298. 
'text,' but to include some of its forms and functions. Accordingly, one would have to transform the creative writing part in such a way that it can include some aspects of its analytical counterpart, not in order to diminish its 'textuality, but in order to enrich it with its dialectical other. And, of course, the same would apply to the critical analysis part so that the practice-based $\mathrm{PhD}$ would then be one work having two separate parts, which each include elements of the opposite pole. In this way, the stereotypical distinction between the 'infinite profundity' of the creative dimension and the 'inevitable simplification' of the analytical dimension might be overcome.

Besides this fundamental rethinking of the necessary entanglement of creative writing and critical analysis, the mixt has at least two other advantages. Firstly, it is an approach that can be applied to the work itself as to its different paratexts - namely the network of verbal and visual elements that 'surrounds' the work ${ }^{18}$ - such as for instance the title, the blurb, the colophon, etc. This is a crucial move in the deconstruction of conventional barriers between writing spaces. Generally speaking, a paratext is not supposed to be structured by the same literary mechanisms as the text itself. (In many cases, as we know it, the paratext is not written by the author herself, but by the publisher, who is the legal owner of the paratext, contrary to the text whose intellectual ownership exclusively belongs to the author.) But it seems logical to expand the deconstruction of the textual difference between creative writing and critical thinking to the editorial difference between text and paratext, which should not be kept apart from the work on the text itself.

Secondly, the mixt also escapes the traditional division of reading and writing. The tension between lisible and lecturable or 'writing' and 'text' - all these terms are used here in the sense coined by Ricardou-do not exclusively characterises the work of either the reader or the writer. Both are constantly facing similar questions to the point that the very difference between reading and writing becomes as infinitely dialectic as any of the other distinctions discussed above. In the mixt, the difference between reading and writing does not fade out, on the contrary. Reading and writing become alternate moments of a more general approach of text processing, each moment of reading translating into a new moment of writing and vice versa. For all these reasons, the mixt is a good concept for further discussions on the shift from the classic creative writing programme to new forms of practice-based research in literature.

18 Gérard Genette, Paratexts: Thresholds of Interpretation (1987), translated by Jane E. Lewin. Cambridge: Cambridge University Press, 1987. 


\section{Bibliography}

Barthes, Roland, S/Z. An Essay (1970), translated by Richard Miller. New York, NY: Farrar, Straus and Giroux, 1974.

Barthes, Roland, The Pleasure of the Text (1972), translated by Richard Miller. New York, NY: Farrar, Straus and Giroux, 1975.

Caduff, Corina, "Literature and Artistic Research," in: Corina Caduff et al., eds., Art and Artistic Research. Zurich: Scheidegger \& Spiess, 2009, pp. 98-105.

Dällenbach, Lucien, The Mirror in the Text (1975), translated by Jeremy Whitely. Chicago, IL: The University of Chicago Press, 1977.

Doubrovsky, Serge, The New Criticism in France (1966), translated by Derek Coltman. Chicago, IL: The University of Chicago Press, 1973.

Flaubert, Gustave, The Letters of Gustave Flaubert, 1857-1880 (1887-1893), translated and ed. by Francis Steegmuller. Cambridge, MA: Belknap Press, 1984.

Genette, Gérard, Paratexts, Thresholds of Interpretation (1987), translated by Jane E. Lewin. Cambridge: Cambridge University Press, 1987.

James, Henry, The Art of the Novel: Critical Prefaces (1909). Chicago, IL: The University of Chicago Press, 2011.

McGurl, Mark, The Program Era. Cambridge, MA: Harvard University Press, 2009.

Motte, Warren F., Oulipo: A Primer of Potential Literature. McLean, IL: Dalkey Archive, 1986.

Poe, Edgar Allan, "The Philosophy of Composition" (1846), in: The Complete Poetry of Edgar Allan Poe. New York, NY: Signet Classics, 1996, pp. 503-512.

Ricardou, Jean, La Prise de Constantinople (1965), in: L'intégrale Jean Ricardou. Tome 2: La Prise de Constantinople et autres écrits. 1962-1966. Brussels: Les Impressions Nouvelles 2018, pp. 139-351.

Ricardou, Jean, "La Fiction à mesure," in: Nouveaux Problèmes du roman. Paris: Éditions du Seuil, 1978, pp. 244-351.

Ricardou, Jean, Le Théâtre des métamorphoses. Paris: Éditions du Seuil, 1982.

Ricardou, Jean, "Eleménts de textique (I)," in: conséquences 10 (1987), pp. 5-28.

Ricardou, Jean, "How to Reduce Fallacious Representative Innocence. Word by Word Interview with Michel Sirvent," in: Studies in 2oth-Century Literature 15:2 (1991), pp. $277-298$.

Roussel, Raymond, How I Wrote Certain of My Books (1935), translated by Trevor Winkfield. Cambridge, MA: Exact Change, 2005.

Sartre, Jean-Paul, What is Literature?, translated by Bernard Frechtman. London: Methuen, 1950. 